\title{
Conhecimentos Didático-Matemáticos para Abordagem da Curva Normal no Ensino Médio
}

\author{
Didactic-Mathematical Knowledge to Approach the Normal Curve in High School
}

\author{
André Fellipe Queiroz Araújo*a; José Ivanildo Felisberto de Carvalho ${ }^{\mathrm{a}}$
}

aniversidade Federal de Pernambuco. PE, Brasil.

*E-mail: andrefellipe93@hotmail.com

\begin{abstract}
Resumo
Investigações que tratem do conhecimento do professor de Matemática são sempre pertinentes e necessárias porque podem contribuir para a ressignificação e o melhoramento da prática docente. No presente texto, são discutidos os resultados de um estudo dissertativo que teve o objetivo de investigar os conhecimentos didático-matemáticos de professores de Matemática do Ensino Médio para abordagem da interrelação entre a Estatística e a Probabilidade por meio da Curva Normal. Esse estudo está fundamentado no modelo teórico de Conhecimentos e Competências Didático-Matemáticos do professor - CCDM, desenvolvido no âmbito do Enfoque Ontossemiótico do Conhecimento e da Instrução Matemática - EOS. Em termos metodológicos, essa pesquisa possui abordagem qualitativa, seu universo de participantes foi composto por 12 professores brasileiros de Matemática do Ensino Médio e seu desenrolar é contemplado por um estudo diagnóstico e um encontro formativo. Os resultados apontam que, inicialmente, os professores apresentaram lacunas nos conhecimentos didático-matemáticos sobre o tema. No entanto, por meio da realização do encontro formativo, no qual foi vivenciada a proposta de ensino, eles conseguiram avançar na construção, ressignificação e ampliação de seus conhecimentos didático-matemáticos sobre a inter-relação entre a Estatística e a Probabilidade por meio da Curva Normal. Concluímos que é pertinente o investimento nas formações acadêmicas e em formações continuadas de estudos semelhantes que possibilitem a apropriação e ampliação de conhecimentos didático-matemáticos de professores de Matemática sobre a Estatística e a Probabilidade.
\end{abstract}

Palavras-chave: Estatística. Probabilidade. Curva Normal. Conhecimentos e Competências Didático-Matemáticos. Formação de Professores.

\begin{abstract}
Investigations that deal with the mathematics teacher's knowledge are always relevant and necessary because they can contribute to the reframing and improvement of teaching practice. In the present text, the results of a dissertation study that aimed to investigate the didacticmathematical knowledge of high school mathematics teachers to approach the interrelationship between Statistics and Probability through the Normal Curve are discussed. This study is based on the theoretical model of Teacher's Competences and Didactic-Mathematical KnowledgeCCDM, developed within the scope of the Ontosemiotic focus to Knowledge and Mathematical Instruction - EOS. In methodological terms, this research has a qualitative approach, its universe of participants was composed of 12 Brazilian high school mathematics teachers and its course is contemplated by a diagnostic study and a formative meeting. The results show that, initially, teachers had gaps in didactic-mathematical knowledge on the topic. However, through the formative meeting, in which the teaching proposal was experienced, they managed to advance in the construction, reframing and expansion of their didactic-mathematical knowledge about the interrelationship between Statistics and Probability through the Curve Normal. We conclude that it is pertinent to invest in academic training and in continuing training in similar studies that enable the appropriation and expansion of didactic-mathematical knowledge of mathematics teachers on statistics and probability.
\end{abstract}

Keywords: Statistic. Probability. Normal Curve. Knowledge and Skills Didactic-Mathematics. Teacher Training.

\section{Introdução}

Frequentemente, nos deparamos com uma gama de dados e informações de natureza estatística e probabilística sobre diferentes aspectos que permeiam nossas vidas e que exigem de nós, enquanto cidadãos, habilidades e conhecimentos necessários para interpretar e compreender o mundo ao nosso redor. Essas informações evidenciam que os conhecimentos estatísticos e probabilísticos se constituem como saberes essenciais para o desenvolvimento de habilidades, reflexões, argumentações e senso crítico que possam propiciar, aos indivíduos, a capacidade de analisar, interpretar e compreender uma variedade de fenômenos, dados e informações, além de favorecer a tomada de decisões e fazer previsões que influenciam na sua vida pessoal e social.

Nesse contexto, acreditamos que, na etapa da escolaridade básica, hão de ser sistematizadas possibilidades para o desenvolvimento do letramento estatístico e probabilístico (GAL, 2002; 2005), favorecendo a apropriação e compreensão dos significados dos conceitos relativos a essas duas áreas de conhecimento. Logo, compreendemos que a consolidação desse desenvolvimento perpassa pela formação inicial e continuada dos professores de Matemática.

Em paralelo, destacamos que a Base Nacional Comum Curricular (BRASIL, 2018), principal documento orientador para o ensino no Brasil, propõe que o processo de ensino e aprendizagem da Estatística e da Probabilidade na Educação Básica deve ser iniciado já nos primeiros anos do Ensino 
Fundamental, e, em seguida, aprimorado e ampliado no Ensino Médio. Esse documento, em linhas gerais, destaca a necessidade da abordagem de conceitos, fatos e procedimentos relativos a essas áreas de conhecimentos que estão presentes em muitas situações-problema do nosso dia a dia.

No entanto, com relação ao processo de ensino e aprendizagem da Estatística e da Probabilidade na Educação Básica, alguns estudos apontam lacunas nesse processo. Santana (2016) destaca que o ensino de Estatística ainda é pautado, por muito docentes, em uma abordagem de ensino que não promove a articulação com a Probabilidade e enfatiza os conteúdos da Estatística Descritiva, abordados com ênfase para a aplicação de algoritmos e técnicas operatórias. Já Utsumi, Cazorla e Kataoka, (2014) indicam que ainda falta uma preparação mais adequada dos professores que atuam na Educação Básica para possibilitar que os mesmos possam ir além do domínio conceitual e passem a adotar ações metodológicas que tornem interessante aos alunos o estudo de conteúdos da Estatística.

Batanero e Díaz (2012) constataram que geralmente o ensino de Probabilidade tem como foco unicamente o tratamento de técnicas operatórias e procedimentos mecanizados, em detrimento a um ensino contextualizado que propicie a abordagem dos significados do conceito de probabilidade, sua utilidade e aplicação em situações do nosso cotidiano. Corroborando com as informações supracitadas, Carvalho (2017) pontua que os professores apresentam dificuldades tanto com o conceito de Probabilidade na perspectiva da Matemática, como da sua didática; advoga, entretanto, que mediante processos formativos adequados, os professores avançam na construção e ressignificações dos seus conhecimentos matemáticos e didáticos sobre Probabilidade.

Diante desse cenário, acreditamos que é pertinente a realização de investigações que tratem dos conhecimentos de professores relativos ao campo estatístico e probabilístico, considerando que os mesmos exercem um papel primordial no processo de ensino e aprendizagem da Matemática, sendo os principais responsáveis por apresentar o conhecimento matemático. Assim, focamos nesse estudo no conceito da Curva Normal, por considerá-la o principal modelo de análise de dados presente na Inferência Estatística (Batanero, Tauber \& Sánchez, 2004), e por acreditar que seu processo de ensino e aprendizagem possibilita a abordagem da inter-relação entre a Estatística e a Probabilidade, áreas que, comumente, são ensinadas de forma totalmente independente por muitos docentes, na Educação Básica.

Nesse sentido, defendemos uma abordagem no Ensino Médio da escolarização básica que considere as etapas de uma pesquisa estatística com dados reais que podem ser tratados e articulados com a noção da Curval Normal e com questões probabilísticas, e que este tema faça parte dos conhecimentos dos professores de Matemática para a abordagem desse modelo e de situações-problemas com contextos reais, estudando e analisando os dados estatísticos e as noções de aleatoriedade e de probabilidades.

Diante disso, o presente estudo teve o objetivo de investigar os conhecimentos didático-matemáticos de professores de Matemática do Ensino Médio para abordagem da inter-relação entre a Estatística e a Probabilidade por meio da Curva Normal. Para tanto, a pesquisa tem como fundamento teórico o modelo de Conhecimentos e Competências Didático-Matemático do professor - CCDM, (Pino-Fan \& Godino, 2015; Godino, Batanero, Font \& Giacomone, 2016), que está embasado no Enfoque Ontossemiótico do Conhecimento e da Instrução Matemática - EOS, (Godino, 2012). A partir desse modelo, os autores defendem que para o professor de Matemática exercer a sua função docente, faz-se necessário o domínio de conhecimentos e competências que englobam tanto o conhecimento matemático, como também o conhecimento sobre o ensino da Matemática.

\section{A Curva Normal e Alguns Estudos Antecedentes Sobre o seu Ensino e Aprendizagem}

De acordo com Bayer, Echeveste, Bittencourt e Rocha (2005), a Estatística é classificada como a ciência que se ocupa da coleta, organização, análise e o tratamento de dados e informações, além de lidar com situações que envolvem incerteza, ou seja, situações não-determinísticas. Ainda segundo estes autores, a Estatística, em sua estrutura, contempla duas áreas de conhecimento: Descritiva e Inferencial.

Em linhas gerais, a Estatística Descritiva reúne métodos para organização, resumo e descrição de dados e informações, como por exemplo: tabelas, gráficos, medidas de tendência central (médias, moda e mediana) e medidas de variabilidade ou dispersão (amplitude, desvio padrão e variância). Em complemento, a área Inferencial é responsável por dar suporte ao pesquisador, apresentando um conjunto de técnicas que buscam caracterizar e projetar o comportamento de uma população a partir dos parâmetros observáveis de uma parte dela, ou seja, uma amostra dessa população.

Nessa direção, subjacentes à Estatística Inferencial estão outros dois campos de conhecimento: a Amostragem e a Probabilidade. O primeiro é identificado como a área responsável pelo desenvolvimento de estudos e técnicas para escolha das unidades populacionais que formarão uma determinada amostra, possibilitando que as mesmas apresentem conclusões que possam caracterizar e representar as suas respectivas populações. Por vez, a Probabilidade é classificada como a área que trata de fenômenos aleatórios, contemplando aspectos de análise combinatória, aleatoriedade, espaço amostral, operações com eventos e comportamentos probabilísticos de variáveis discretas e contínuas (Bayer, Echeveste, Bittencourt \& Rocha, 2005).

Assim, podemos compreender que a Probabilidade, por se ocupar do estudo e modelagem de fenômenos aleatórios, 
está inter-relacionada com a Estatística e serve de alicerce para a Estatística Inferencial, proporcionando a formulação de técnicas e modelos matemáticos que possibilitam o cálculo da probabilidade de eventos, inferir e caracterizar uma população. Nesse sentido, a Distribuição Normal, também chamada de Curva Normal, é considerada o principal modelo probabilístico que descreve o comportamento de variáveis aleatórias contínuas e é uma aproximação de outros tipos de distribuições, como a Binomial, Poisson e T de Student abarcando uma variedade de fenômenos do nosso cotidiano que apresentam uma Distribuição Normal ou aproximadamente normal de dados (Gonçalves, 2014 ; Tauber, 2001). A Curva Normal é definida a partir dos parâmetros média ( e o Desvio padrão) dos dados de uma amostra e graficamente possui a seguinte representação:

Figura 1 - Representação da Curva Normal

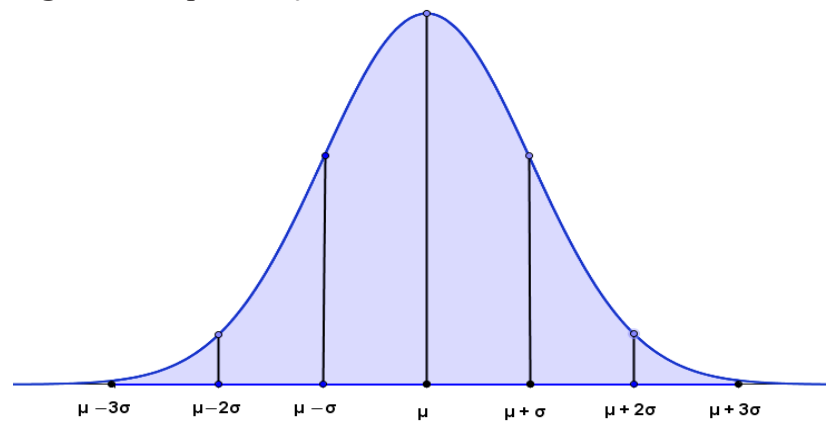

Fonte: Os autores.

A partir dessas informações, em termos matemáticos, devemos compreender que a Curva reúne $100 \%$ dos dados da amostra e a área sob seu gráfico e o eixo das abscissas é sempre igual a 1. Além disso, a Curva Normal possui algumas importantes propriedades: 1) A Distribuição dos dados é simétrica em relação à média (, ou seja, ao centro; 2) Em toda Curva Normal, os valores de média, moda e mediana da amostra coincidem; 3) A Curva Normal possibilita determinar probabilidades associadas aos valores da área de intervalos da distribuição; 4) A probabilidade de uma variável assumir um valor entre dois pontos é determinada pela área sob a curva que os contêm.

No que diz respeito ao processo de ensino e aprendizagem da Curva Normal, abordaremos, a seguir, alguns estudos que versam sobre a compreensão de estudantes e professores sobre este modelo, sua importância e possibilidades de ensino e abordagem em sala de aula.

Tauber (2001) realizou um estudo sobre a Curva Normal com graduandos recém ingressos na Universidade de Granada, na Espanha. Inicialmente, a autora desenvolveu com os estudantes um diagnóstico sobre o tema e percebeu que eles apresentaram inconsistências no conhecimento sobre a Estatística Inferencial, Amostragem e a Curva Normal. Ela aponta que essa dificuldade decorreu do ensino da Estatística na Educação Básica que se voltava principalmente à área Descritiva, não sendo comum os professores explorarem a
Estatística Inferencial e importantes conceitos como a Curva Normal e a Amostragem.

Posteriormente, ela desenvolveu uma sequência didática, pautada na abordagem teórica e na resolução de atividades, tendo como recurso o software Statgraphics, que consiste em um pacote de dados estatísticos reais, que executa e explica funções estatísticas. Com esse método, a autora objetivou ensinar, aos estudantes, os fundamentos teóricos da Curva Normal. Na avaliação do questionário e da sequência didática, Tauber (2001) concluiu que os estudantes apresentaram um avanço e foram capazes de trabalhar com os dados reais, reconhecer e compreender o conceito da Curva Normal e a sua representação e realizar o cálculo de probabilidades associada à Curva.

Por fim, Tauber (2001) defende que o ensino da Curva Normal deve ser iniciado já na Educação Básica, cuja relevância na Estatística e na Probabilidade se deve ao fato de que muitos fenômenos físicos, biológicos e sociológicos do nosso cotidiano podem ser modelados através da Curva Normal, o que permite o seu uso em qualquer área do conhecimento, como também, muitos métodos estatísticos exigem a condição de normalidade para sua correta aplicação.

O estudo de Macedo (2016) teve o objetivo de investigar os conhecimentos de um grupo de professores de Matemática do estado de São Paulo - Brasil. Este grupo incluiu professores do Ensino Fundamental e Médio da Educação Básica, os quais participaram de uma formação continuada sobre o ensino de noções estatísticas relativas à Curva Normal. Os resultados do estudo indicam, inicialmente, que os professores não priorizavam o ensino da Curva Normal em suas aulas e apresentaram concepções inconsistentes sobre os conceitos estatísticos presentes nesse tipo de distribuição. No entanto, após o processo formativo, o autor concluiu que os professores ressignificaram os conceitos estatísticos e compreenderam a importância do ensino da Curva Normal, e assim, ampliaram a base de conhecimentos relativa ao ensino da Estatística.

González, Ojeda e Palacios (2018) realizaram uma pesquisa com dois professores de Matemática do México, um atuante no Ensino Médio e o outro no Nível Superior e ambos possuíam experiência com o ensino de Estatística e Probabilidade e com o ensino da Curva Normal em seus respectivos níveis de atuação. Os autores realizaram uma entrevista semiestruturada e individual com cada professor, na qual a primeira pergunta foi voltada para resolução e explicação de uma situação problema sobre a Curva Normal, as demais perguntas indagaram a forma como os professores abordavam o tópico da Curva Normal e qual livro didático adotavam.

$\mathrm{Na}$ análise das respostas apresentadas, os autores constataram que os professores tiveram dificuldades de interpretar a situação problema e não conseguiram solucionar a questão. Além disso, ficou evidenciado que os dois professores replicavam o discurso apresentado pelos livros didáticos adotados e que o ensino da Curva Normal tinha 
como foco apenas a operacionalização e tratamento das fórmulas e cálculos. Deste modo, os autores concluem que o ensino da Curva Normal, desde a Educação Básica, também deve incluir a compreensão dos significados desse conceito e dos conceitos estatísticos e probabilísticos abarcados nesse modelo em diversos contextos, para que seja possível a correta interpretação dos fenômenos e problemas que fazem uso da Curva Normal.

\section{Modelo de Conhecimentos e Competências Didático- Matemáticos - CCDM}

Com vistas a investigar os conhecimentos didáticomatemáticos de professores do Ensino Médio para abordagem da inter-relação entre a Estatística e a Probabilidade por meio da Curva Normal, adotamos como aporte teórico as ideias Godino e Pino-Fan (2015); Godino, Batanero, Font e Giacomone (2016) sobre o modelo Conhecimentos e Competências Didático-Matemáticos - CCDM, desenvolvido a partir das noções teóricas do EOS (Godino, 2012).

No referido modelo, o conhecimento didático-matemático é classificado como o saber docente relativo à matemática e ao seu ensino e que estão relacionados entre si no processo de ensino e aprendizagem. Já a competência, diz respeito uma ação efetiva do professor realizada em um contexto específico com um propósito determinado. No entanto, diante do nosso objetivo, focamos apenas nos conhecimentos didáticomatemáticos que o professor de Matemática deve possuir para que possa exercer sua prática docente de forma eficiente. A imagem, a seguir, esquematiza e apresenta os componentes e as facetas didático-matemáticos que compõem esse modelo.

Figura 2: Conhecimento didático-matemático

\section{CONHECIMENTO DIDÁTICO - MATEMÁTICO}

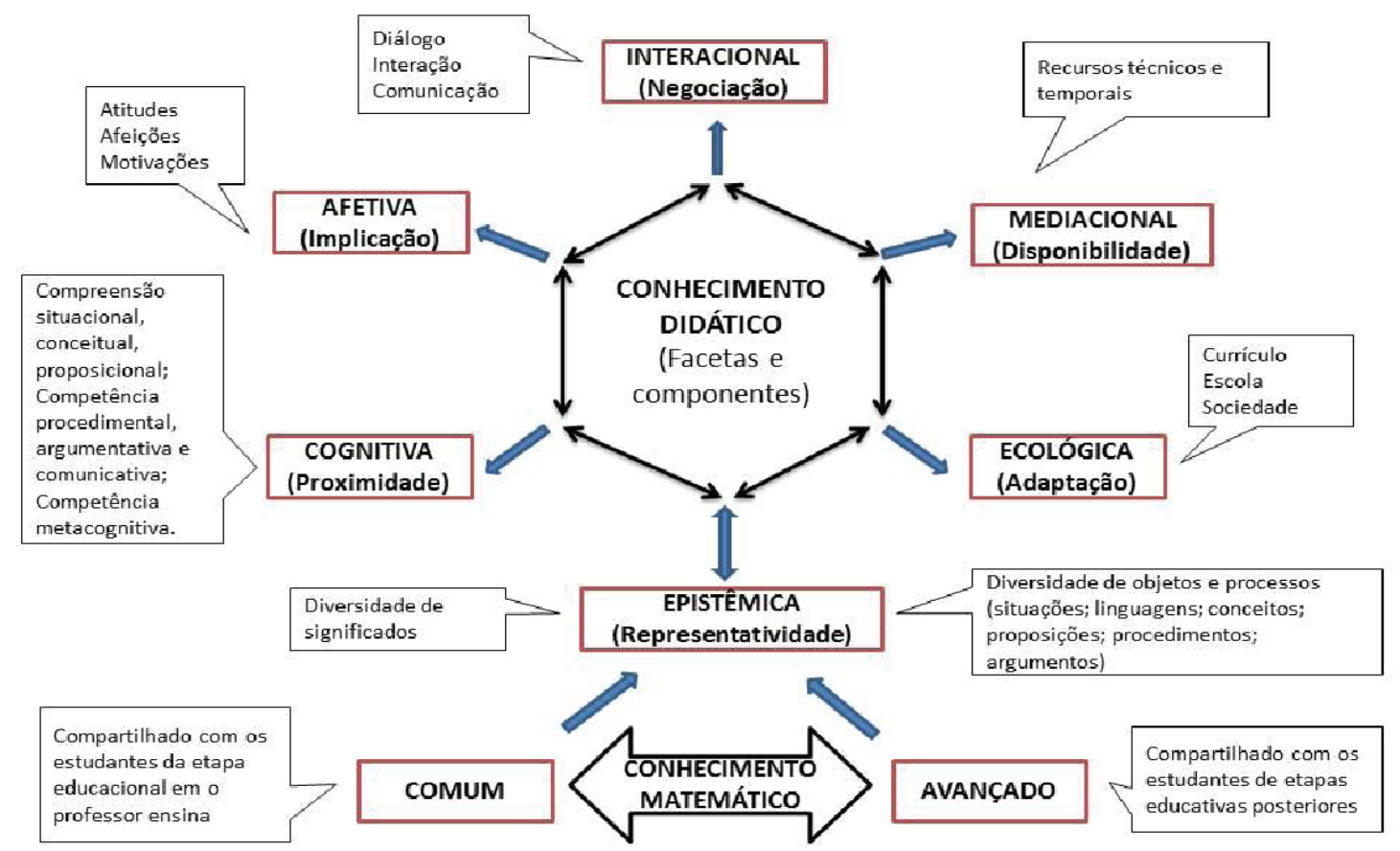

Fonte: Dados da pesquisa.

Discorrendo sobre as características das categorias de conhecimento matemático, Pino-Fan e Godino (2015) enfatizam que o conhecimento matemático comum do conteúdo corresponde ao conhecimento do professor sobre um objeto específico matemático, capaz de resolver problemas ou atividades matemáticas relacionadas a esse objeto e que deve ser abordado com os alunos em cada etapa da escolarização em que o professor se propõe a desenvolver o processo de ensino e aprendizagem sobre esse conteúdo. No ensino da Curva Normal, por exemplo, o conhecimento comum do conteúdo diz respeito ao domínio de conceitos, definições, procedimentos operatórios e algoritmos a serem abordados no Ensino Médio da Educação Básica e suficientemente para resolver problemas e interpretar dados e informações estatísticas e probabilísticas apresentadas nesse tipo de distribuição.

O conhecimento matemático avançado do conteúdo, por sua vez, corresponde ao conhecimento sobre os conteúdos matemáticos que devem ser ensinados nas etapas educativas posteriores. Deste modo, o professor deve ter domínio do conhecimento matemático escolar no nível educacional onde ele ensina, mas também deve ser capaz de articular este conhecimento com aqueles correspondentes que serão abordados em níveis educacionais subsequentes. (Pino-Fan \& Godino, 2015)

Em relação à faceta Epistêmica, a mesma contempla o 
conhecimento matemático que vai além daqueles abarcados pelas categorias "comum" e "avançado" do conteúdo. Assim, diz respeito ao conhecimento sobre a pluralidade de significados que os objetos matemáticos podem assumir, levando em consideração as diferentes situações e contextos que os mesmos estão inseridos, as diversas representações que podem ser mobilizadas e as relações entre os conceitos matemáticos, objetos e processos abarcados em cada situação. Deste modo, a partir desse conhecimento, o professor deve ser capaz, por exemplo, de mobilizar diferentes representações e reconhecer os diversos significados dos objetos matemáticos emergidos durante a resolução. Em nosso caso, esse conhecimento abarca os diferentes significados e representações em que a Curva Normal pode assumir em diversas situações e aplicações, bem como as relações entre os conceitos estatísticos e probabilísticos presentes nesse modelo. A faceta cognitiva, por sua vez, está relacionada com o conhecimento sobre aspectos e a forma como os estudantes aprendem, raciocinam, entendem a Matemática e como progridem na sua aprendizagem. Já a faceta afetiva (emocional), corresponde ao grau de conhecimento sobre aspectos emocionais e comportamentais, como também as crenças e atitudes dos estudantes sobre os objetos matemáticos no processo de ensino e aprendizagem da Matemática. Em continuidade, a faceta mediacional corresponde ao conhecimento sobre a disponibilização e utilização de recursos didáticos (tecnológicos, materiais) que podem ser utilizados para abordagem de conteúdos, a fim de potencializar o processo de ensino aprendizagem. Em relação à faceta interacional, ela corresponde ao conhecimento sobre o ensino da Matemática, organização de atividades para o ensino e os diversos tipos de interações que podem ocorrer na sala de aula, que são consideradas essenciais para o processo de ensino e aprendizagem da Matemática, isto é, alunos com o professor, alunos entre si e alunos com os recursos didáticos. A faceta ecológica, por sua vez, corresponde ao conhecimento sobre a relação dos conteúdos matemáticos com outras disciplinas, o currículo proposto para o ensino de Matemática e os fatores do cotidiano, como sociais, incluindo a comunidade escolar, políticos e econômicos que estão subjacentes ao processo de ensino e aprendizagem da Matemática. (Pino-Fan \& Godino, 2015)

Por fim, Pino-Fan e Godino (2015) e Carvalho (2017) destacam que todos esses componentes e facetas didáticomatemáticos estão relacionadas entre si no processo de ensino e aprendizagem da Matemática e assim, faz-se necessário que o professor tenha domínio sobre todos eles. Desta forma, ao exercer a prática docente o professor deve ser capaz de mobilizar, aplicar e reconhecer tais dimensões.

\section{Metodologia}

A presente investigação se constituiu de um estudo dissertativo que, em termos metodológicos, utiliza uma abordagem qualitativa. Sobre esse tipo de abordagem, Oliveira
(2011, p.28) classifica "como sendo um processo de reflexão e análise da realidade através da utilização de métodos e técnicas para compreensão detalhada do objeto de estudo em seu contexto histórico e/ou segundo a sua estruturação".

O universo de participantes dessa pesquisa foi composto por 12 professores de Matemática do Ensino Médio da rede pública do estado de Pernambuco, localizado na região Nordeste do Brasil. Os mesmos estão identificados no presente texto pela letra $\mathrm{P}$ e um índice subscrito: $\mathrm{P}_{1}, \mathrm{P}_{2}, \mathrm{P}_{3}, \ldots, \mathrm{P}_{12}$, para fins de apresentação e tratamento de dados. A escolha por professores desse nível de escolarização se deve ao fato de o estudo da Curva Normal, através do ensino da Estatística e da Probabilidade, ser recomendado para essa etapa de ensino nas diretrizes para a Educação Básica veiculadas por Pernambuco (2013) e Brasil (2018).

Além disso, o desenvolvimento desse estudo foi pautado em duas etapas. Na primeira, aplicamos um questionário diagnóstico de forma impressa aos 12 professores participantes, o qual propiciou a investigação dos conhecimentos didáticomatemáticos iniciais desses professores sobre a inter-relação entre a Estatística e a Probabilidade por meio da Curva Normal. Na segunda etapa, com base nas análises dos dados obtidos no questionário diagnóstico, realizamos um encontro formativo no qual desenvolvemos uma proposta de ensino, voltada para a abordagem articulada entre a Estatística e a Probabilidade por meio da Curva Normal, com o objetivo de investigar a construção/ampliação dos conhecimentos didático-matemáticos dos professores sobre o referido tema.

Esse encontro de formação foi pautado através de uma vivência de 4 momentos que contemplaram a realização de três atividades impressas, em forma de questionários, e uma sistematização teórica sobre o tema, seguidas de discussões coletivas sobre as ideias abordadas em cada momento. Todos esses momentos contaram com a intervenção do pesquisador, as atividades impressas foram recolhidas, as discussões e socializações foram gravadas e estão analisadas e discutidas no presente texto.

A escolha pelo questionário como tipo de instrumento foi por entender que o mesmo "é considerado um importante instrumento de pesquisa por fornecer subsídios reais do universo ou da amostra pesquisada" Oliveira (2011, p. 44). Ademais, como critério de análise de dados, classificamos as respostas dos professores aos questionários a partir de três categorias, a saber: Resposta Adequada (RA); Resposta Parcialmente Adequada (RPA) ou Resposta Inadequada (RI). A opção por esse método de classificação se deu por acreditar que o mesmo possibilita, de modo satisfatório, identificar, compreender e caracterizar os dados coletados nos questionários das duas etapas da pesquisa.

\section{Resultados e Discussão}

Como discorrido na seção anterior, a primeira etapa da pesquisa foi destinada a aplicação de um questionário 
diagnóstico aos participantes do estudo. Esse questionário contemplou oito perguntas relativas ao conhecimento didático-matemático sobre a inter-relação entre a Estatística e a Probabilidade envolvida pelo modelo da Curva Normal.
O gráfico, a seguir, representa o desempenho e a classificação das respostas dos professores em categorias de acordo com as facetas de conhecimento didático-matemático contemplado em cada uma das questões.

Figura 3 - Respostas dos professores ao Questionário Diagnóstico

\section{Frequência}
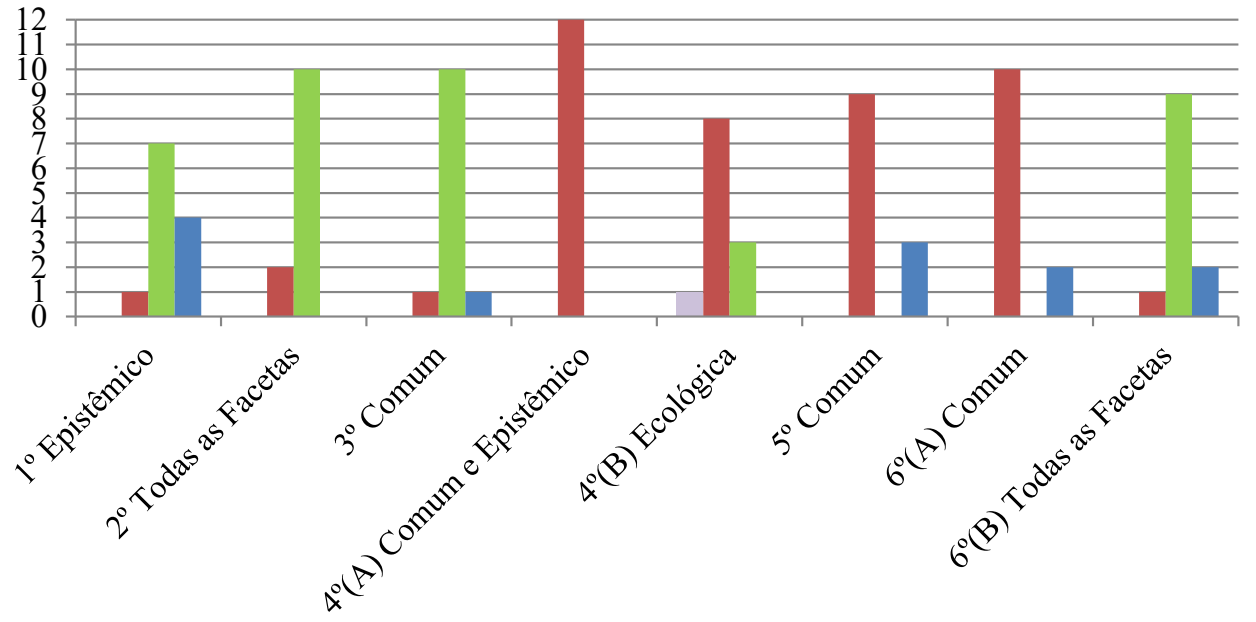
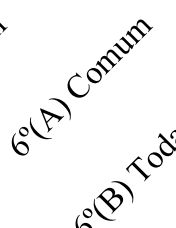

Tipo de

Conhecimento

e Categoria de

Resposta

\footnotetext{
Não Respondeu
}

Fonte: Os autores.

Diante desses dados, nota-se uma predominância no desempenho dos professores de respostas dos tipos Parcialmente Adequada e Inadequada. Chamamos atenção para o fato de que quatro questões com maior frequência de respostas inadequadas três delas envolvem o conhecimento comum do conteúdo. $\mathrm{Na} 4^{\circ}(\mathrm{A})$ questão, por exemplo, indagamos aos professores de que modo eles conceituavam a Curva Normal e constatamos que todos eles apresentaram respostas inadequadas.

Evidenciou-se, nesta etapa, que os 12 professores não conheciam o conceito da Curva Normal e que, possivelmente, não tiveram formação voltada para este conceito durante suas trajetórias acadêmicas, acarretando na não apropriação do mesmo. Logo, esses dados também indicam que, provavelmente, tais professores não abordam esse conceito no Ensino Médio da escolarização Básica, quando lecionam os conteúdos de Estatística e da Probabilidade. Como apontam Gonçalves (2014) e Macedo (2016), ainda não é comum, no Brasil, o conceito da Curva Normal, sua representação gráfica, os conceitos estatísticos e o cálculo de probabilidades presentes nesse modelo matemático, serem abordados nessa etapa de ensino. Além disso, por meio da análise das respostas às demais questões, verificamos que a maioria dos professores demonstrou não ter domínio sobre o conhecimento epistêmico relativo à relação teórica entre a Estatística e a Probabilidade, nem sobre o conhecimento matemático comum sobre conceitos de Amostragem, Amplitude e Desvio-Padrão. No entanto, percebemos que, dentre as medidas de centralidade e dispersão, o conceito de média, demonstrou ser aquele que os professores mais conheciam, dominavam e que, possivelmente, mais abordavam em sala de aula.

Em relação ao conhecimento didático, os professores demonstraram não ter domínio sobre o conhecimento relativo a um dos critérios da Faceta Ecológica, isto é, as orientações curriculares veiculadas por Pernambuco (2013) e Brasil (2018) que contemplam a abordagem da Curva Normal no Ensino Médio.

Ademais, na questão onde solicitamos que os professores elaborassem uma proposta de aula que articulasse a Estatística e a Probabilidade para o Ensino Médio, eles se limitaram em apresentar atividades como recurso didático para a abordagem da referida relação e, dessa forma, emergiram noções apenas do conhecimento didático relacionado à faceta Mediacional. Em acréscimo, alguns professores evidenciaram noções de conhecimento didático envolvendo as facetas Cognitiva, Afetiva, Mediacional e Interacional quando indagados sobre como avaliariam e procederiam a discussão com os alunos a partir das respostas apresentadas por grupos de estudantes a uma situação-problema envolvendo a Curva Normal. Dessa forma, emergiram noções didáticas de como iriam questionar as respostas dos estudantes e a forma como buscariam interagir com os mesmos para a discussão sobre o tema.

Em linhas gerais, a análise realizada na primeira etapa da pesquisa indicou, veementemente, que a maioria dos professores não tinha domínio conceitual e não ensinava a Estatística articulada com a Probabilidade e nem a Estatística Inferencial, bem como o conceito da Curva Normal, contemplando os conceitos estatísticos e probabilísticos presentes nesse modelo. Essas conclusões sinalizaram que os professores investigados necessitavam de um 
acompanhamento formativo que oportunizasse o estudo sobre o tema pautado.

\section{O Encontro Formativo: Ampliando e Ressignificando Conhecimentos}

A partir do diagnóstico levantado, demos prosseguimento ao estudo realizando o Encontro Formativo, no qual desenvolvemos uma proposta de ensino para a abordagem da articulação entre a Estatística e a Probabilidade por meio da Curva Normal. A realização dessa proposta se deu através de um encontro com duração de quatro horas que, por sua vez, foi subdividido em quatro momentos que contemplaram a realização de três atividades, a abordagem de uma sistematização teórica sobre o tema em pauta e discussões coletivas sobre as ideias abordadas em cada momento. Destaca-se ainda que essa segunda etapa contou com a participação voluntária de 7 dos 12 professores que responderam ao questionário diagnóstico, os quais foram organizados em duas duplas e um trio para a realização das atividades.

No primeiro momento, a primeira atividade se apresentou com o objetivo de instigar nos professores a reflexão sobre o conhecimento matemático comum sobre os conceitos de média aritmética, moda, mediana, desvio-padrão e probabilidade, os quais estão presentes no modelo da Curva Normal. Inicialmente, cada professor apresentou a sua altura (cm), para que todos os grupos tivessem acesso a esse dado de todos os professores participantes do encontro. A escolha da altura $(\mathrm{cm})$ como variável a ser trabalhada foi dada pela mesma se tratar de uma variável contínua e a Curva Normal descrever comportamento de variáveis com essa característica.

Em seguida, os professores foram convidados a responder duas questões. A primeira solicitava que cada grupo determinasse a média aritmética, a moda, a mediana e o desviopadrão das alturas do conjunto de professores participantes daquele encontro. A segunda questão solicitou que cada grupo apresentasse a probabilidade de se escolher ao acaso um dentre todos os professores participantes e ele possuir a altura maior que a média do conjunto. Ao verificarmos as respostas apresentadas pelos grupos, constatamos que todas se classificam na categoria Resposta Adequada, isto é, os professores apresentaram de modo adequado o cálculo das medidas de centralidade e de dispersão e o cálculo de probabilidade solicitados na questão, demonstrando possuírem noções do conhecimento matemático Comum sobre esses conceitos. $\mathrm{O}$ encontro prosseguiu com a socialização e discussão entre o pesquisador e os professores sobre as questões presentes nessa primeira atividade. Destacamos, aqui, os diálogos mais pertinentes ocorridos nesse momento:

[...] Pesquisador: Como vocês têm abordado esses conceitos nas aulas de Matemática?

$\mathrm{P}_{4}$ : Eu abordo muito de forma mecânica.

$\mathrm{P}_{10}$ : Eu também.

$\mathrm{P}_{12}^{10}:$ Eu também.

[...] Pesquisador: Como vocês têm abordado o conceito de probabilidade no Ensino Médio? Vocês conseguem relacionálo com a Estatística?

$\mathrm{P}_{1}$ : Acho que não relaciono não. Eu abordo sempre com uma razão mesmo. Aquela definição dos casos favoráveis sobre todos os casos possíveis, podendo o resultado ser escrito por uma fração ou por uma porcentagem.

Pesquisador: Os demais professores ensinam dessa forma ou de uma abordagem diferente?

Demais professores: Assim também.

Diante da discussão realizada, evidenciou-se que os professores estavam habituados a abordar a Estatística independente da Probabilidade e com foco apenas na aplicação mecânica das fórmulas e técnicas operatórias de conceitos estatísticos e probabilísticos (Santana, 2016). No entanto, eles refletiram na necessidade de também compreender e abordar, em sala de aula, as medidas de dispersão relacionadas com as de centralidade, os significados desses conceitos inseridos em diferentes contextos, e como se dá a relação entre a Estatística e a Probabilidade.

$\mathrm{Na}$ sequência, a sistematização se iniciou com o estudo teórico sobre a Estatística enquanto ciência, contemplando a área Descritiva e Inferencial, ressaltando nesta última, os conceitos de amostragem, amostra e sua relação com a Probabilidade, a partir das ideias de Bayer et al. (2005). Nessa etapa, foi possível perceber que os professores abordavam em suas aulas, unicamente, a Estatística Descritiva com foco na interpretação e análise de gráficos e tabelas, no cálculo das medidas de centralidade e, menos frequentemente, as medidas de dispersão. No entanto, passaram a compreender o conhecimento epistêmico sobre a Estatística enquanto ciência e a sua relação com a probabilidade, refletindo na necessidade e importância de abordar a Estatística Inferencial. Além disso, também contemplaram noções de conhecimento didático para a abordagem da Estatística Inferencial em sala de aula, como podemos observar no recorte do diálogo, a seguir:

Pesquisador: E como podemos trabalhar a Inferencial em sala de aula?

$\mathbf{P}_{4}$ : Acho que poderíamos fazer tipo uma pesquisa, coletando dados como você fez aqui inicialmente com as alturas. E a partir desses dados poderíamos interagir em sala com os alunos, perguntando a eles, o processo da pesquisa e esses conceitos que você falou, a amostra, a amostragem, as medidas de tendência central e de dispersão também.

$\mathbf{P}_{\mathbf{8}}$ : Acho isso também. Poderia fazer uma pesquisa com os próprios colegas da escola, de outras turmas, ou pessoas que moram nos bairros e diante dos dados que eles forem coletando, podemos trabalhar o conceito da amostra, na ideia que ela vai representar o todo, não com a precisão de $100 \%$, porque vai ter sempre uma margem de erro, uma probabilidade associada a isso, mas mesmo assim, vai mostrar aproximadamente o todo.

Nas discussões sobre o tema, podemos perceber que também emergiram noções de conhecimento didático envolvendo as facetas Interacional, Mediacional e Ecológica, ao proporem o desenvolvimento de pesquisas com dados reais, tópico presente nos documentos curriculares para o ensino de estatística na disciplina de Matemática, como recurso didático para a interação e abordagem dos conceitos de amostragem, 
amostra e de como a probabilidade está subjacente a Estatística Inferencial.

Prosseguimos a sistematização com a apresentação do modelo da Curva Normal, com o objetivo de proporcionar, aos professores, a apropriação do conhecimento comum e o conhecimento epistêmico sobre a Curva Normal, isto é, seu conceito, significados e representações. De início, percebemos que os professores não tinham o entendimento sobre o conhecimento matemático comum relativo ao conceito de variável estatística e deste modo, apresentamos aos mesmos a definição proposta por Cazorla, Magina, Gitirana e Guimarães, (2017, p.29), as quais concebem uma variável estatística como "uma característica da população que assume diferentes valores ou categorias". A partir disso, focamos na variável quantitativa do tipo contínua, a qual na ótica das referidas autoras se trata de uma variável numérica cujos valores são resultantes de uma mensuração, como por exemplo, a massa $(\mathrm{kg})$, altura $(\mathrm{cm})$ e renda familiar $(\mathrm{R} \$)$.

Diante desse entendimento, apresentamos o conceito da Curva Normal e sua representação gráfica. Na sequência, utilizando exemplos de Curvas Normais que retratam fenômenos do nosso cotidiano, apresentamos os conceitos estatísticos, probabilísticos e as propriedades matemáticas que estão presentes na Curva Normal, isto é, as medidas de centralidade e dispersão, a probabilidade associada à área da Curva e das demais propriedades que também estão abordadas na seção da Curva Normal no presente texto. Através da discussão realizada, foi possível perceber que os professores passaram a compreender o conceito da Curva Normal, além de serem capazes de fazer as leituras estatísticas e assimilar os significados de cada gráfico e dos conceitos das medidas de centralidade e dispersão abarcadas por cada um deles.

Em seguida, procedemos com o cálculo de probabilidades na Curva Normal retomando a discussão que toda Curva Normal reúne $100 \%$ dos dados da amostra e a área sob seu gráfico e o eixo das abscissas é sempre igual a 1, tornando possível determinar probabilidades associadas aos valores da área de intervalos da distribuição de modo que a área sob a curva entre dois pontos é a probabilidade de uma variável normalmente distribuída tomar um valor entre esses pontos. Após isso, explicamos o cálculo de probabilidades utilizando os métodos da tabela normal padronizada $\mathrm{Z}$ e o software Geogebra, dois recursos que permitem o cálculo da área de um determinado intervalo sob a Curva e a probabilidade de um elemento da amostra pertencer a esse determinado intervalo. Logo, também buscamos propiciar aos professores, uma oportunidade para os mesmos se apropriarem do conhecimento didático envolvendo a faceta Mediacional, apresentando a eles, a tabela e o Geogebra como recursos didáticos para o ensino desse tema em sala de aula.

Para finalizar, abordamos as diretrizes curriculares que orientam o ensino da Curva Normal no Ensino Médio da escolarização básica, veiculadas por Pernambuco (2013) e Brasil (2018). No entanto, os professores, afirmaram não conhecer tais recomendações curriculares e, a partir dessa abordagem sobre o currículo, buscamos oportunizar a eles, a apropriação do conhecimento didático envolvendo a faceta Ecológica que contempla o conhecimento sobre o currículo proposto para o ensino de Matemática. A seguir, apresentamos um recorte do debate que veio em decorrência:

Pesquisador: Colegas professores, diante do que estudamos aqui sobre o conceito da Curva Normal, o cálculo de probabilidades e as orientações curriculares para o seu ensino, o que vocês podem dizer sobre esse tema, pensando no seu ensino em sala de aula?

$\mathbf{P}_{7}$ : Eu achei bem interessante. Eu não conhecia a Curva Normal. Nunca tinha

estudado, nem na graduação, mas é interessante entender o quanto assim... a Curva

Normal ela está presente no nosso dia a dia em diversas situações. Também não conhecia essas recomendações do currículo. É bem interessante.

$\mathbf{P}_{2:}$ Eu já tinha ouvido falar, mas não sabia o que era a Curva Normal, mas também achei muito interessante, a ideia das medidas de tendência central, a média, moda e mediana, do desvio padrão, da probabilidade, a relação entre eles e o significado de cada um na Curva Normal, é muito interessante e como a professora falou, isso está bem presente no nosso cotidiano. Acho importante abordar isso em sala sim.

A partir dos relatos desses professores, podemos compreender que os mesmos não conheciam o conceito da Curva Normal, incluindo sua representação gráfica, os conceitos das medidas de centralidade e dispersão, os cálculos probabilísticos presentes na Curva Normal e as recomendações curriculares oficiais para o seu ensino na Educação Básica. Além disso, ficou evidente, como já observado no estudo diagnóstico, que eles não estudaram tais conceitos, em suas respectivas formações acadêmicas e, consequentemente, não os ensinavam em suas aulas.

Em continuidade, o terceiro momento do encontro formativo foi destinado para a realização da segunda atividade, a qual foi composta por três questões. As duas primeiras tiveram o objetivo de analisar o conhecimento matemático Comum e o conhecimento Epistêmico relativo à Curva Normal, envolvendo alguns conceitos estatísticos e probabilísticos presentes na mesma e o cálculo de probabilidades associados a intervalos sob a Curva Normal. Já a terceira questão teve como objetivo analisar o conhecimento didático dos professores envolvendo todas as facetas: Epistêmica, Cognitiva, Afetiva, Mediacional, Interacional e Ecológica, a partir de uma resposta de um estudante a uma situação problema envolvendo o conceito da Curva Normal. A seguir, apresentaremos as questões da segunda atividade, concomitantemente, com a discussão dos resultados das análises.

Questão 1 - O gráfico, a seguir, representa a distribuição das alturas(m) de uma amostra de 307 pessoas. A partir dessas informações, é correto afirmar que se escolhemos uma pessoa dessa amostra ao acaso, a maior probabilidade é que ela tenha a altura entre $[1,62 ; 1,66$ [? Justifique sua resposta! 


\section{Histograma de frequências}

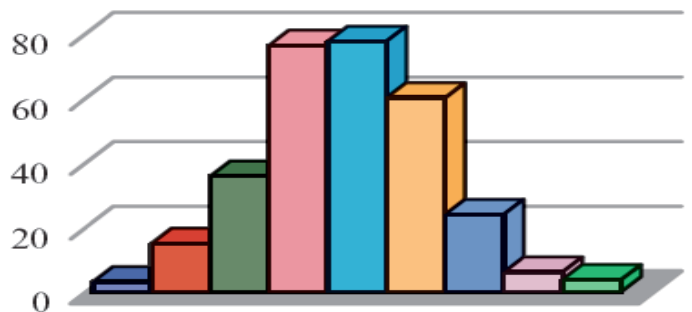
ㅁ $[1,46 ; 1,50[$
ㅁ $[1,50 ; 1,54[$
ㅁ $[1,54 ; 1,58[$
ㅁ $[1,58 ; 1,62[$
ㅁ $[1,62 ; 1,66[$
ㅁ $[1,66 ; 1,70[$
ㅁ $[1,70 ; 1,74[$
ㅁ $[1,74 ; 1,78[$
ㅁ $[1,78 ; 1,82[$

Fonte: São Paulo, 2014

Ao analisarmos as respostas dos grupos, constatamos que todos os professores responderam de modo adequado por pontuarem ser verdadeiro o questionamento, justificando que o intervalo, em questão, se tratava da moda dos dados da amostra, como podemos observar na imagem, a seguir.

Figura 4 - Resposta RA da Dupla 2 à $1^{\text {a }}$ questão da Atividade 2

Sin. O inturucls $[1,62 ; 1,66[$ corroponde inedidos de tundinuos entmis no USO a MODA.

[Sim. O intervalo [ 1,62, 1,66 [ corresponde a medidas de tendência centrais, no caso a moda.]

Fonte: Dupla 2, 2019.

Deste modo, infere-se que os professores se apropriaram do conhecimento matemático Comum e do conhecimento Epistêmico sobre a Curva Normal e as medidas de tendência central presentes nela, pois eles foram capazes de reconhecer que o ponto central do gráfico também representa a moda da amostra, o valor mais frequente, e, consequentemente, há maior probabilidade desse valor ser escolhido se escolhermos uma pessoa dessa amostra ao acaso.

Questão 2 - Em uma escola, um professor realizou um estudo em que foi medida a altura, em $\mathrm{cm}$, de todos os estudantes do Ensino Fundamental. Ele concluiu que esses estudantes possuíam a média e o desvio padrão da altura iguais a, $155 \mathrm{~cm}$ e $4 \mathrm{~cm}$, respectivamente. A partir dessas informações, determine:

a) Se o professor escolher um aluno do Ensino Fundamental ao acaso, qual a probabilidade que o aluno escolhido tenha a altura entre $155 \mathrm{~cm}$ e $164 \mathrm{~cm}$ ?

b) qual a probabilidade de um aluno do Ensino Fundamental ter a altura maior ou igual a $155 \mathrm{~cm}$ ?

Na segunda questão, apresentamos uma situação problema abordando os dados com a média e o desvio padrão das alturas de uma amostra de estudantes. A partir dessas informações, no item (a), utilizando os dois parâmetros da Curva Normal, a média e o desvio padrão, os professores deveriam utilizar a tabela da Curva Normal padronizada (z) e calcular a área sob a curva entre o intervalo solicitado. No item (b), os professores deveriam reconhecer que o intervalo maior ou igual que 155 $\mathrm{cm}$, ou seja, a média representa a metade da curva e, portanto, a área é igual a 0,5 ou $50 \%$ de probabilidade.

Ao analisarmos as respostas dos professores, verificamos que nos dois itens, todos os grupos responderam de forma adequada. Logo, no item (a), eles foram capazes de determinar corretamente a probabilidade de se escolher um estudante ao acaso e ter a altura entre o intervalo de $155 \mathrm{~cm}$ e $164 \mathrm{~cm}$. Já no item (b), foram capazes de reconhecer, intuitivamente, a probabilidade de se escolher um estudante ao acaso e ele ter a altura maior ou igual que a média da amostra dos estudantes. Em termos de exemplo, apresentamos abaixo a resposta adequada do trio de professores para o item (b):

Figura 5 - Resposta RA do Trio de professores à $2^{\mathrm{a}}$ questão (b) da Atividade 2

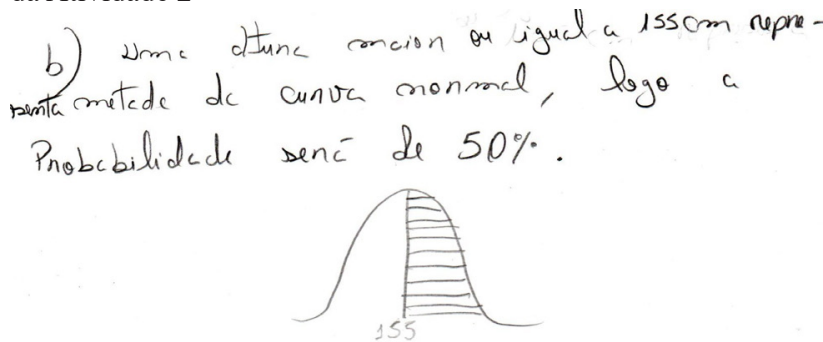

b) Uma altura maior ou igual a $155 \mathrm{~cm}$ represente metade da curva normal, logo a probabilidade será de $50 \%$.

Fonte: O Trio (2019).

Diante dessa figura, podemos perceber que ao responder à questão, o grupo fez uma representação do gráfico da Curva Normal para exemplificar a área, que corresponde à probabilidade da metade da Curva. Diante disso, concluímos, mais uma vez, que os professores se apropriaram do conhecimento matemático Comum e do conhecimento Epistêmico relativo ao conceito da Curva Normal, contemplando os conceitos da média e desvio padrão presentes na Curva Normal, a representação gráfica, bem como, o cálculo de probabilidades.

Questão 3 - Caros professores, imaginem que vocês estão ensinando a Curva Normal em uma turma do Ensino Médio. A seguir, está a resposta de um estudante a um problema envolvendo este tema. Quais seriam suas avaliações e explicações para a resposta desse estudante? Como vocês procederiam com a discussão em classe diante da resposta apresentada?

Questão: Os pesos dos alunos de uma escola distribuem-se normalmente, com média aritmética igual a $62,5 \mathrm{~kg}$ e desvio padrão igual a $1,2 \mathrm{~kg}$. Se a probabilidade de escolhermos, ao acaso, um aluno dessa escola que possua o peso no intervalo entre $62,5 \mathrm{~kg}$ a $63,7 \mathrm{~kg}(62,5 \mathrm{~kg}+1,2 \mathrm{~kg})$ é igual aproximadamente $34 \%$, a probabilidade de alunos que, provavelmente, encontram-se entre $62,5 \mathrm{~kg}$ a $61,3 \mathrm{~kg}(62,5 \mathrm{~kg}$ $-1,2 \mathrm{~kg}$ ) é igual, maior, ou menor que $34 \%$ ? Por quê? 
Figura 6 - Resposta de um estudante a um problema sobre a Curva Normal

Émenor. Porque ocredito que os estudontes que estao entre 62,5 Kg e 63,7 Kg Tîm mais chance de shem excolhidos.

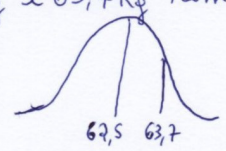

[É menor. Porque acredito que os estudantes que estão entre 62,5 $\mathrm{kg}$ e $63,7 \mathrm{~kg}$ têm mais chance de seres escolhidos. ]

Fonte: Os autores.

A terceira questão, por sua vez, apresentou uma resposta incorreta de um estudante a uma situação-problema envolvendo a Curva Normal. Desse modo, objetivamos analisar o conhecimento didático envolvendo todas as facetas, isto é, as noções de conhecimento didático sobre os aspectos e a forma como o estudante entende a Curva Normal, suas crenças e atitudes sobre esse objeto matemático, os recursos didáticos e os tipos de interações que poderiam ser utilizados para a discussão e abordagem do tema com a classe de estudantes.

Assim, ao analisarmos as respostas do grupo de professores, observamos que todos eles apresentaram respostas do tipo parcialmente adequadas, pois suas considerações se detiveram apenas a avaliar o conhecimento e a crença do estudante diante do objeto matemático contemplado na questão, e, deste modo, apresentaram noções de conhecimento didático relativo às facetas Afetiva e Cognitiva, não pontuando a forma como prosseguiria a discussão em classe, como podemos observar na figura, a seguir.

Figura 7 - Resposta RPA da Dupla 1 à $3^{\text {a }}$ questão da Atividade 2

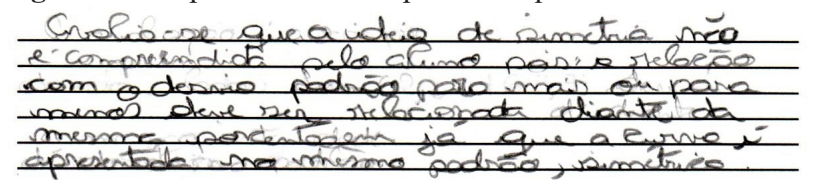

Avalia-se que a ideia de simetria não é compreendida pelo aluno pois a relação com o desvio padrão para mais ou para menos deve ser relacionada diante da mesma porcentagem, já que a

Curva é apresentada no mesmo padrão, simétrica.

Fonte: Dupla 12019.

Diante disso, podemos perceber que os professores analisaram corretamente a resposta de um estudante, mas não destacaram a forma como prosseguiria a discussão com a turma. No entanto, durante a discussão sobre essa questão, emergiram noções de conhecimento didático sobre as facetas Epistêmica, Cognitiva, Afetiva, Interacional, Mediacional e Ecológica, onde foi destacada a importância de interagir com os estudantes, questionando o porquê da resposta apresentada, levando em consideração o seu contexto, a suas crenças, atitudes e significados sobre a Curva Normal, e a utilização de recursos didáticos, como por exemplo, o Geogebra, para o ensino do tema presente na questão.

Por fim, no quarto momento, o qual contemplou a terceira atividade, os professores foram convidados a apresentar, individualmente, quais as contribuições que o estudo realizado no encontro formativo, proporcionou para o desenvolvimento de seus conhecimentos na perspectiva do conhecimento matemático e no conhecimento para o ensino da temática, ou seja, o didático. Logo, as respostas para essa atividade não se apresentam categorizadas porque elas denotam a opinião dos professores sobre a relevância do estudo realizado e as possíveis contribuições do mesmo para a construção e/ou aprimoramento de seus conhecimentos didático-matemáticos sobre o tema.

Nesse sentido, na perspectiva do conhecimento matemático, os professores apontaram que o estudo desenvolvido propiciou o entendimento da relação entre Estatística e a Probabilidade, por meio da Estatística Inferencial, contemplando importantes conceitos, até então, pouco conhecidos, como a Amostragem e Amostra. Além disso, destacaram a construção do conhecimento matemático sobre a Curva Normal, tendo em vista que eles não conheciam este modelo, como também a compreensão dos conceitos e significados das medidas de tendência central e de dispersão e o cálculo de probabilidades a partir da Curva Normal.

Com relação ao conhecimento didático, os professores destacaram que o estudo proporcionou o entendimento de novas possibilidades didáticas para o ensino da Estatística e da Probabilidade no Ensino Médio e da relação entre ambas através da Curva Normal, abarcando a compreensão de aspectos didáticos relacionados ao currículo de Matemática para a referida etapa de ensino, dos recursos didáticos que podem ser utilizados para robustecer a prática docente e as diferentes maneiras de interagir e abordar essa temática com os estudantes em sala de aula.

\section{Conclusão}

Partindo do modelo de Conhecimentos e Competências Didático-Matemáticos do professor - CCDM, esse estudo teve por objetivo de investigar os conhecimentos didáticomatemáticos de professores de matemática do Ensino Médio para abordagem da inter-relação entre a Estatística e a Probabilidade por meio da Curva Normal. No que diz respeito aos dados coletados por meio do questionário diagnóstico, inferimos que, de forma geral, os professores apresentaram lacunas sobre os conhecimentos didático-matemáticos necessários para a abordagem desse conceito.

Entretanto, através da realização do encontro formativo, no qual foram realizadas atividades e uma sistematização teórica que abarcaram os conhecimentos didático-matemáticos sobre a inter-relação entre a Estatística e a Probabilidade por meio da Curva Normal e as possibilidades didáticas para o seu processo de ensino e aprendizagem no Ensino Médio, concluímos que os professores conseguiram avançar na construção, ressignificação e ampliação de seus conhecimentos didático-matemáticos sobre essa temática. Diante desses resultados, acreditamos que é pertinente o investimento em 
formações acadêmicas e continuadas de estudos semelhantes, que possibilitem a apropriação e ampliação de conhecimentos didático-matemáticos de professores de Matemática do Ensino Médio relativa ao campo Estatístico e Probabilístico e, mais especificamente, a Inferência Estatística e o modelo da Curva Normal, como também favorecer a qualidade das ações docente em sala de aula, potencializando as tarefas didáticopedagógicas e de aprendizagem, em favor do letramento estatístico e probabilístico dos estudantes.

\section{Referências}

Bayer, A., Echeveste, S., Bittencourt, H. \& Rocha, J. (2005) Preparação do formando em Matemática-licenciatura plena para lecionar Estatística no Ensino Fundamental e Médio. Recuperado de http://www.nutes.ufrj.br/abrapec/venpec/ conteudo/artigos/3/doc/p508.doc

Batanero, C., Tauber, L. \& Sánchez, V. (2004). Students' reasoning about the normal distribution. In D, Ben-Zvi \& $\mathrm{J}$, Garfield (Eds), The challenge of developing statistical literacy, reasoning and thinking (pp. 257-276). doi: https:// doi.org/10.1007/1-4020-2278-6

Batanero, C. \& Díaz, C. (2012). Training school teachers to teach probability: reflections and challenges. Chilean Journal of Statistics, Granada, 3(1), 3-13. Recuperado de http://chjs. mat.utfsm.cl/volumes/03/01/Batanero_Diaz(2012).pdf

Brasil. (2018). Base Nacional Curricular Comum, Ministério da Educação e da Secretaria de Educação. Brasília, Brasil.

Carvalho, J. I. F. (2017). Um estudo sobre os conhecimentos didáticos-matemáticos de probabilidade com professores de matemática dos anos finais do ensino fundamental. Tese de doutorado em Educação Matemática, Universidade Anhanguera de São Paulo. São Paulo, Brasil.

Cazorla, I., Magina, S., Gitirana, V. \& Guimarães, G. (2017). Estatística para os anos iniciais do ensino fundamental, (Ed. Sociedade Brasileira de Educação Matemática - SBEM). Brasília. Recuperado de http://www.sbem.com.br/files/ ebook_sbem.pdf

Gal, I. (2002). Adult's Statistical Literacy: Meanings, Components, Responsibilities - Appeared, In Internacional Statistical Review, 70 (1), 1-33. doi: 10.1111/j.17515823.2002.tb00336.x

Gal, I. (2005). "Towards probability literacy" for all citizens: building blocks and instructional dilemas. In Jones, G. (Ed.) Exploring Probability in Schools: Challenges for Teaching and Learning (pp. 39-63). New York, NY: Springer. doi: 10.1007/0-387-24530-8_3
Godino, J. D. (2012). Origen y aportaciones de la perspectiva ontosemiótica de investigación en didáctica de la matemática. In Estepa, A., Contreras, A., Deulofeu, J., Penalva, M. C. F., García J. \& García, O. L., XVI Investigación en Educación Matemática XVI- SEIEM (pp. 49 - 68). Jaén

Godino, J D., Batanero, C., Font, V. \& Giacomone, B. (2016). Articulando conocimientos y competencias del profesor de matemáticas: el modelo CCDM. In Fernández, C., González, J. L., Ruiz, F. J., Fernández T. \& Berciano, A. (Ed.) XX Investigación en Educación Matemática - SEIEM. (pp. 288297). Málaga.

Gonçalves, P. (2014). Uma abordagem da distribuição normal através da resolução de uma situação problema com a utilização do software geogebra. Dissertação de Mestrado profissional em Matemática, Universidade Federal de Goiás. Goiás, Brasil.

González, Y. K. Ojeda, A. M. \& Palacios, J. L. (2018). Comprensión de Profesores de la Distribución Normal. Acta Latinonamerica de Matemática Educativa, 31 (2),

Macedo, R. C. (2016), Conhecimentos de professores de matemática sobre o processo de ensino e de aprendizagem de noções estatísticas-curva normal. Dissertação Mestrado em Educação Matemática, Universidade Anhanguera de São Paulo. São Paulo, Brasil.

Magalhaes, M. N. \& Lima, A. C. P. (2004). Noções de Probabilidade e Estatística. ( $6^{\circ}$ edição). Universidade de São Paulo. São Paulo, Brasil.

Oliveira, M. M. (2011). Como fazer projetos, relatórios, monografias, dissertações, teses. Elsevier. Rio de Janeiro.

PERNAMBUCO. (2013). Parâmetros para a Educação Básica do Estado de Pernambuco, Secretaria Estadual de Educação, Pernambuco.

Pino-Fan, L. \& Godino, J. D. (2015). Perspectiva ampliada Del conocimiento didáctico-matemático Del profesor. Paradigma, 36 (1), (pp.87-109), Venezuela.

Santana, M. S. (2016). Traduzindo Pensamento e Letramento Estatístico em Atividades para Sala de Aula: construção de um produto educacional, Bolema, 30(56), 1165-87. doi: http://dx.doi.org/10.1590/1980-4415v30n56a17

Tauber, L. (2001) La Construcción del Significado de La Distribución Normal a partir de Actividades de Análisis de Datos. Tese de Doutorado, Universidad de Servilla.

Utsumi, M. C., Cazorla, I. M. \& kataoka, V. Y. (2014). Statistical training of pre-service teachers with application in school practice. American Review of Mathematics and Statistics, 2 (1), 55-66. doi: https://doi.org/10.1007/978-3-319-23470-0_3 